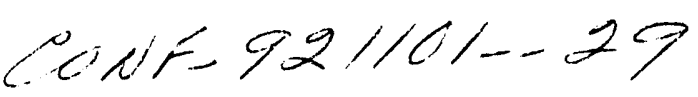

\title{
IS IT POSSIBLE TO DEMONSTRATE COMPLIANCF. WITH THE REGULATIONS FOR HIGH-LEVEL-WASTE REPOSITORIES?
}

SAND $--92-2335 \mathrm{C}$

DE93 U05375

\section{FELTON W. BINGHAM}

Department 6312, Sandia National Laboratories, Albuquerque, NM 87112

\section{ABSTRACT}

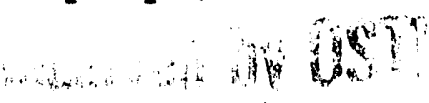

The regulations that currently govern repositories for spent fuel and high-level waste require demonstrations that are sometimes described as impossible to make. To make them will require an understanding of the current and the future phenomena at repository sites; it will also require credible estimates of the probabilities that the phenomena will occur in the distant future. Experts in many fields-earth sciences, statistics, numerical modeling, and the law-have questioned whether any amount of data collection can allow modelers to meet these requirements with enough confidence to satisfy the regulators. In recent years some performance assessments have begun to shed light on this question because they use results of actual site investigations. Although these studies do not settle the question definitively, a review of a recent totalsystem assessment suggests that compliance may be possible to demonstrate. The review also suggests, however, that the demonstration can be only at the "reasonable" levels of assurance mentioned, but not defined, in the regulations.

\section{WHY THE QUESTION ARISES}

When the U.S. Environmental Protection Agency issued its standard for repositories containing radioactive wastes, the technical community immediately raised questions about it. Indeed, the questions had been under discussion for years, and the issuance of the standard (as 40 CFR 191 in the U.S. Code of Federal Regulations) simply brought them to the attention of more people. One of the most frequently asked questions was whether anyone could show convincingly that a proposed repository would comply with the standard. This question arose not merely because the standard was complex. It arose mainly because to show compliance with it would require the gathering and analysis of information in ways that much of the technical community was not comfortable with.

To see why the technical community was concerned, it is helpful to review the standard briefly. Under U.S. law, the Environmental Protection Agency (the EPA) was. required to issue a standard for use in determining whether a proposed repository, constructed deep underground, would adequately protect the general environment from offsite releases of radioactive material. The law required this standard to be "generally applicable." The EPA therefore wrote a standard that could be used in determining the . $\because$.. safety of reposit ies holding different kinds of waste in different locations.

This general standard directly addressed the problem, which had perplexed the technical community for some time, of how to estimate releases that might occur in the distant future as long-lived radionuclides decay. The standard did so by requiring, first, that an applicant for permission to establish a repository estimate the releases that 
might occur during the 10,000-year period after the repository had been closed. That requirement itself attracted some objection from the technical community: some persons felt that 10,000 years is too long for credible prediction, no matter what methods are used for the predicting. The standard, however, went further. It required, second, that applicants treat all the significant processes and events that might affect the ability of a repository to isolate waste. And it required, third, that applicants treat them probabilistically. Not only must applicants estimate releases from the repository; they must also estimate the probabilities of occurrence of those releases.

Much of the standard provoked discussions and questions, but the latter two requirements were the main source of the question that is the title of this paper. To identify all the events and processes that would be significant during 10,000 years would, some persons felt, stretch the predictive capabilities of the earth and social sciences beyond their reasonable bounds. Moreover, even persons who were not skeptical of those predictive capabilities tended to wonder whether anyone could make technically convincing determinations of the probabilities of occurrence.

The standard provided an answer to these questionings. Stated as briefly as possible, the answer was this: the standard did not require complete assurance. What the standard required was "reasonable expectation" that a proposed repository would meet the probabilistic limits on releases during 10,000 years. By using this phrase, the EPA tried to make a standard that clearly recognizes the difficulties in stretching the earth sciences. The supplementary guidance that the EPA attached to the standard expanded this recognition; it gave additional explanations about the level of detail that the EPA would consider sufficient evidence of compliance.

Nevertheless, the basic question remains-at least partly because the standard, by design, does not fully define "reasonable assurance." This paper suggests an answer to the question.

\section{THE BASIS FOR THE ANSWER GIVEN IN THIS PAPER}

Answers to the basic question-is it possible to show compliance?-are emerging as the technical community gains experience with the standard. Since 1985, when the standard first appeared, several preliminary studies have applied the standard to generic sites and to real sites. These studies have supplied insights into the technical reasonableness of the standard.

This paper draws on one of those studies: the recent assessment of the performance of a potential repository system at Yucca Mountain in Nevada. ${ }^{1}$ That study uses actual field data describing the site and is therefore a concrete example of the difficulties that may arise in determining compliance.

The study is instructive for another reason as well. Critics often cite three particular technical problems as concrete examples of the difficulties with the standard. The Yucca Mountain site contains features whose treatment requires solutions to those problems, which are the following:

1. The treatment of different conceptual models that describe the behavior of a site and are equally consistent with field data. 
2. The collection of enough site data to allow the behavior of the whole repository system to be modeled acceptably.

3. The treatment of uncertainties in the data describing the site.

The Yucca Mountain study has had to wrestle with these problems, and its solutions to them help to answer the basic question. To emphasize the solutions, this paper reviews only a few parts of the study; the solutions developed in those parts are the basis for this paper's answer to the fundamental question.

The study makes no claim to solve these problems definitively. In fact, it insists that it is a preliminary effort intended as guidance for future work and not as a determination of compliance. The set of data on which the study rests is not complete; it will expand greatly as the Yucca Mountain Project conducts its program of site characterization. To suggest whether a Yucca Mountain repository would be in compliance is therefore not the intention of this review. The intention is to show what the recent study reveals about the ability of a scientific investigation to come to grips with the problems in the standard.

The rest of this section briefly reviews three of the activities performed as part of the study and reported in Reference 1. Each of these activities contributes some insight into the solution of one or more of the three technical problems.

\section{Activity 1: treating two conceptual models of flow}

The hydrologic investigations of Yucca Mountain have not yet established the precise manner in which water flows there. The mountain itself consists of layers of unsaturated volcanic tuff, which overlie a deep aquifer. The repository would be in the unsaturated rock about 300 meters below the surface and roughly 200 meters above the aquifer. The unsaturated rock contains little water, the scarcity of which is one of the reasons the site appears attractive. How this water moves through the unsaturated rock is important to the behavior of a repository. If the water moves downward only slowly and is held tightly within the rock matrix, it has little ability to reach buried waste, dissolve it, and carry it to the aquifer. If, on the other hand, most of the water movement occurs in local zones of saturation (perhaps near fractures or other features), the water might reach buried waste more easily; free-flowing water at a container of waste might dissolve its contents and transport the dissolved material to the aquifer. Some interpretations of field data suggest a third possibility: that the net movement of water in at least some parts of the site occurs mostly through the gas phase and may even be upward instead of downward. Such a possibility offers less potential for waste transport than the first two interpretations. Hydrologists who study the site are able to suggest even more interpretations, and the selection of the correct interpretation mosit await further data from the site-characterization program.

These three interpretations are radically different. A mathematical model of repository behavior that incorporates one of them will clearly produce estimates of releases that differ from estimates made with another of them. The technical community has grown accustomed to calling such interpretations "alternative conceptual models," and the uncertainty about how to handle them contributes to criticism of the EPA standara. The criticism is especially applicable at Yưcea Mountain, where it is hard to design and interpret the field tests and experiments 
needed to establish whether any one of the conceptual models is correct. Whichever model is correct, the proounts of water available for field tests are so small that the tests have difficulty establishing how the water actually moves.

Yucca Mountain, then, poses a test of whether it is possible to show compliance when uncertainties in conceptual models are present. The recent study reported in Reference 1 dealt with this uncertainty by taking several steps that may be an acceptable framework for dealing with it in future license applications.

As its first step, the study constructed two separate, well-defined mathematical models. Each expresses quantitatively one of the two conceptual models that describe the flow of water in liquid form.

One of these models is the "composite-porosity" model. It assumes that water flows uniformly and ubiquitously downward through the mountain. Its mathematical expression is a version of Darcy's law appropriate for unsaturated flow in a rock that contains numerous fractures, as some layers of rock at Yucca Mountain do. To use this model to produce estimates of releases, the study reviewed the available data on the parameters that appear in the mathematical expressions; it then selected values or distributions of values for those parameters. In particular, it also assumed a range of values for the flux of water at depth in the mountain-i.e., the amount of water that moves downward through the repository and reaches the underlying aquifer. An important feature of this model is that, given the available information on the ability of the rock matrix and the fractures to carry water, the flow appears to be mostly in the matrix except at very high flow rates.

The other model is the "weeps" model. It assumes that the water moves through both rock matrix and fractures but that, because of local saturation effects, a significant amount of the water flows through the fractures. The fracture flow is faster than the generally slow motion predicted by the composite-porosity model, and for that reason it would move radionuclides to the aquifer in a shorter time. If a container of waste happened to intersect a flowing fracture, it would receive more water than it would receive from the uniformly distributed flow in the composite-porosity model. On the other hand, the weeps model delivers water only to those containers that intersect flowing fractures; the composite-porosity model predicts a more nearly uniform delivery to all the containers.

The use of each of these models requires some modification to the part of the release calculations that describes the interaction of water with waste containers. Those calculations, which provide the "source term" for transport calculations, are different for at least two reasons: (1) The number of packages that the water can reach is different in the two models. (2) The mechanisms by which water can reach a container are differcist in saturated and unsaturated rock.

In choosing values and distributions for the parameters in both of the flow models and in the source-term model, the authors of the study generally made conservative choices. When field data were not definitive, they made choices that would tend to produce larger releases of radioactive material.

With these models in hand, the study proceeded to a second step. -It combined the models separately with its other models describing parts of the radionuclide-release process: the source-term models already mentioned, a model for geochemical effects during the transport of dissolved material, and a model for transport through the underlying aquifer. With all these models it calculated estimates of radionuciide 
releases under the assumption that first one and then the other of the two flow models is an accurate description of flow at the site.

Finally, the study produced, as its third step, a "complementary cumulative distribution function" for the releases estimated with the two models. The EPA standard, in its guidance section, recommends that an applicant construct this function, commonly called the "CCDF," as the way to determine compliance. A repository system meets the standard if the CCDF for its releases lies below and to the left of the limits shown in Figure 1.

Figure 1 also shows the CCDFs estimated with each of the two flow models. Neither model predicts releases that would violate the standard. The two curves, one for each model, lie well to the left of the noncompliance region of the graph. Furthermore, because the models were constructed with a conservative bias, the authors of the study believe the two curves overestimate the releases.

This process, then, is an example of a solution to technical problem 1. It shows how different, contradictory conceptual models may contribute to an assessment of compliance with the EPA standard, even when the modelers lack enough data to choose between the models. If the estimates made with neither model threaten to violate the standard, the need to make a fully defensible choice between the models disappears. And if the construction of the models makes conservative choices, the analysis supplies "reasonable expectation" that the site is in compliance.

The process is also a partial example of a solution to technical problem 3 , the handling of uncertainty. A fourth step, which the study does not perform as fully as its authors hope to do in the future, is uncertainty studies, in which the modelers examine the response of the release estimates to the uncertainties in parameter ranges and in the conceptual models. Figure 1 shows, of course, the response of the release estimates to uncertainty in the choice of conceptual model, since the two models represent fairly extreme interpretations of the liquid flow at Yucca Mountain. The uncertainty studies can be more elaborate, however. By varying fundamental features of the two models, the studies can investigate more fully whether there is any appreciable possibility that the curves might actually lie closer to the limits.

It is important to realize, however, that the curves in Figure 1 already express the effects of uncertainty. They were created by sampling from probability distributions for the parameters in the models-distributions that explicitly express uncertainties and ranges of possible values. For example, the distribution assumed for flux at depth was extended to higher fluxes than current data would suggest. The authors intended this wider-than-justified distribution to reflect uncertainty in current data and the possibility that future climates may be wetter.

These curves do not, of course, establish the suitability of Yucca Mountain. The site characterization may turn up new insights that invalidate the models or suggest additional possibilities; scientists who review the study will disagree about the details of the modeling and the choices of parameter values. Furthermore, the CCDF for the final comparison against the standard will have to include all modes of release, not just the aqueous modes shown in Figure 1. The lesson to be learned from this analysis is that conservative estimates made with different models are likely to be amenable to analysis under the EPA standard. The standard does not appear to make compliance impossible to show when alternative, contradictory concepiual models are available or when considerable uncertainty is present. 


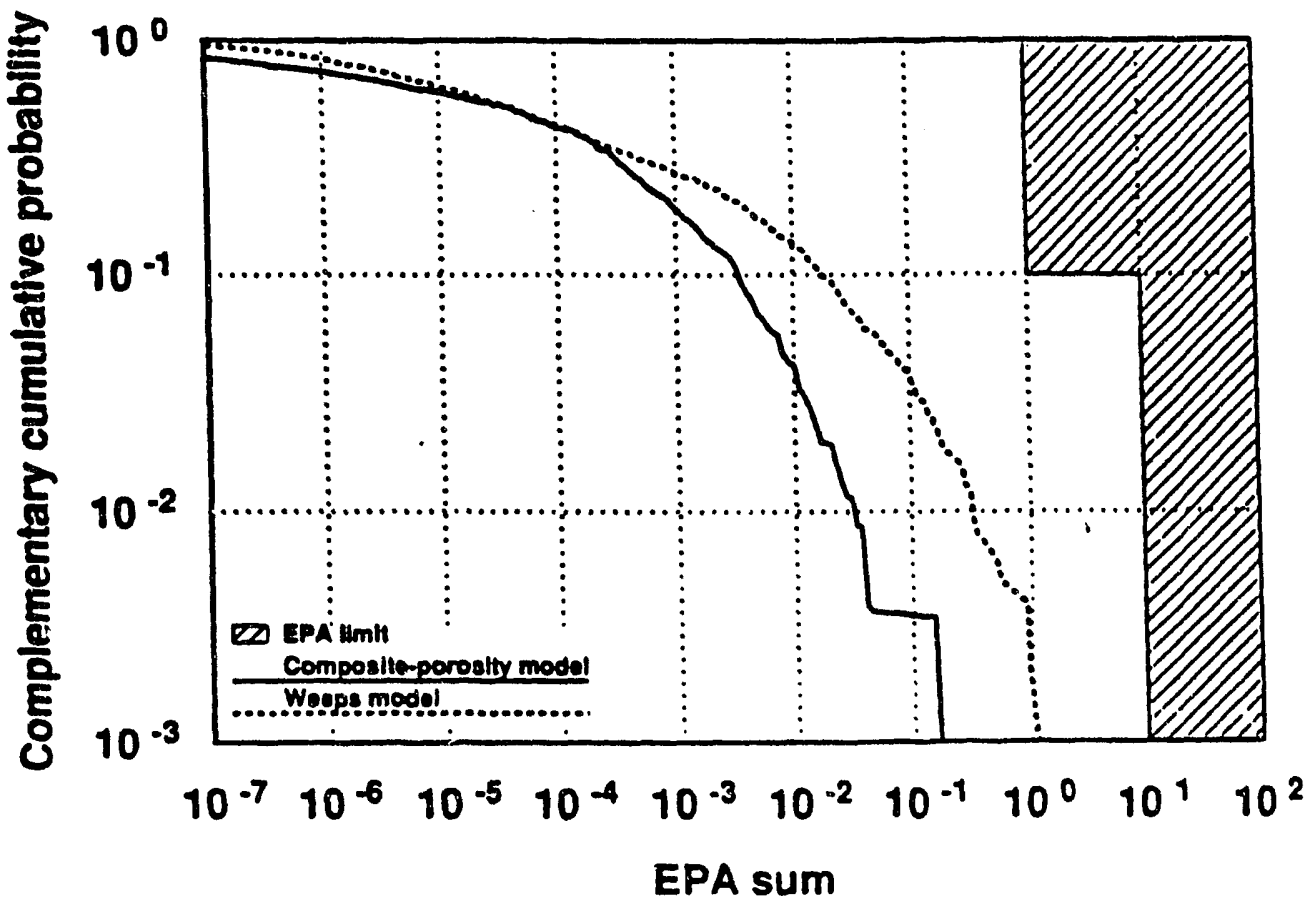

Figure 1. Complementary cumulative distribution functions for releases from a Yucca Mountain repository along aqueous pathways. Separate functions are shown for the two conceptual models of flow.

\section{Activity 2: treating igneous intrusion}

Among the most frequent objections to the EPA standard is the uncertainty about the amount of data that an applicant must acquire in order to defend the estimates of compliance-especially the data that support estimates of probabilities. Clearly, regulators will demand a firm underpinning of the estimates of compliance, and that underpinning must rest on a thorough understanding of the natural composition of a repository site. Can an applicant, even in principle, gather enough data to demonstrate compliance? The recent assessment ${ }^{1}$ of Yucca Mountain offers some examples of answers to this question. One section of the report, because it rests on field observations that have been conducted over several years, offers a particularly instructive glimpse of what may be acceptable. That section estimates the effect of basaltic igneous activity on the performance of a repository. It uses site data and general understanding of such activity to calculate a CCDF. Like all the calculations of CCDFs, the igneous-intrusion analysis has to model the ways in which a repository might be affected and to estimate their probabilities of occurrence. The calculations in Reference 1 use conservative interpretations of field data in doing these two tasks.

Previous studies have suggested many ways in which an igneous intrusion could

$\therefore \quad \therefore$ affect a repository. For example, an intrusion might create a dike that passes through

the repository and directly carries 'waste to the surface; an intrusion might alter the hydraulic properties of the underground flow system or change the chemical characteristics of the waste. The authors of the study, wishing to estimate the more severe effects among these possibilities, chose to estimate the consequences of the 


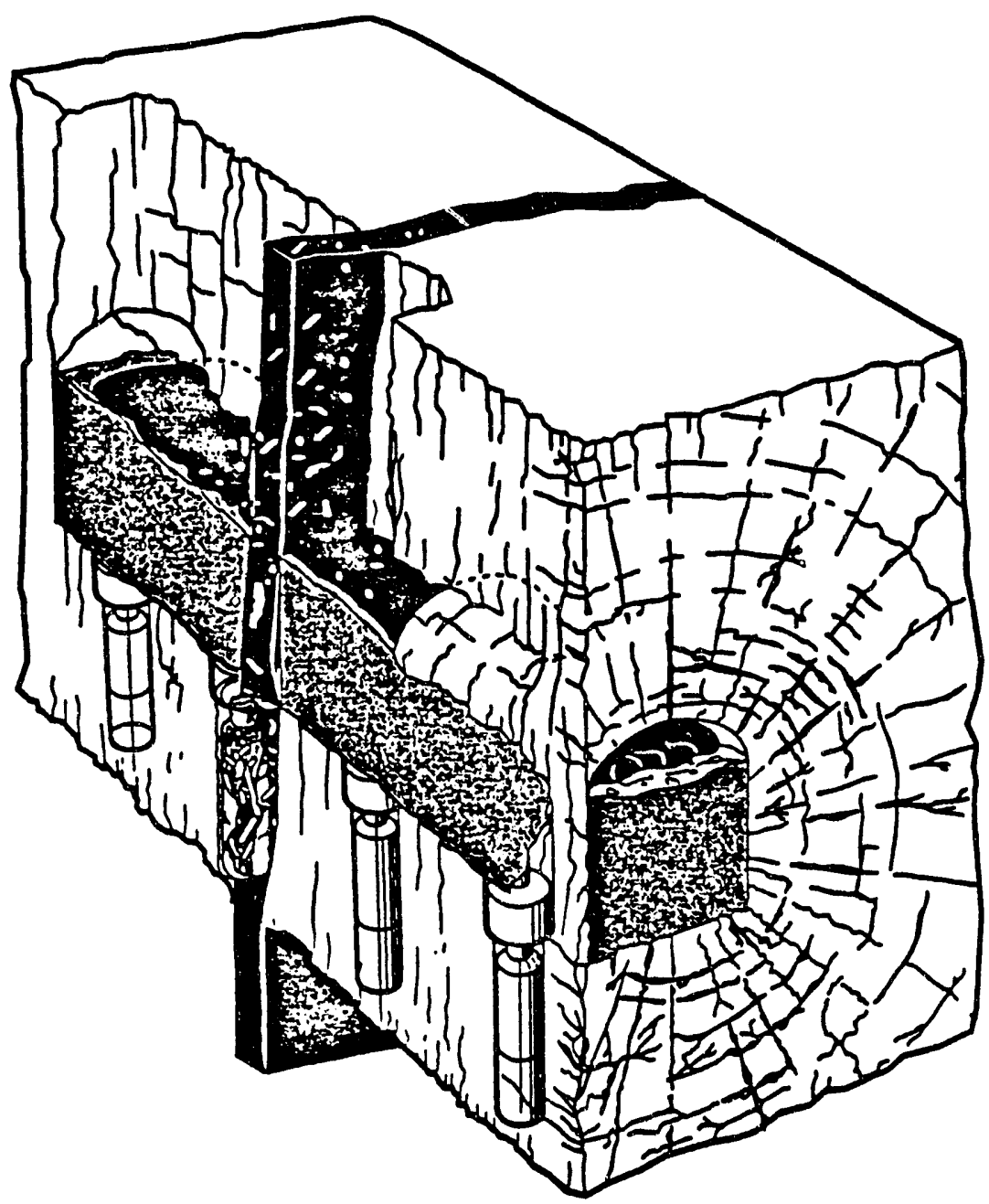

Figure 2. The igneous-intrusion sequence: a dike penetrates a repository, intercepts a container of waste, and carries fragments of radioactive material up to the ground surface above the repository.

following sequence: an igneous intrusion acts directly on the underground repository, creating a dike that fragments waste and carries it upward through a basaltic cone at the ground surface. Figure 2 shows this sequence.

To model this sequence defensibly, the authors sought a detailed description of the likely behavior of a dike. Field evidence allowed them to assign a probability distribution to the range of widths that the dike might have. Because the width of a dike at Yucca Mountain is not likely to be greater than 3 meters or so, the dike can intercept only a small number of containers unless it happens to run along a row of containers. To estimate the dike's effects, the analysts therefore had to model its orientation, which they treated as a random variable. They constructed a probability distribution for this variable by using field observations. Another important variable in the modeling was the amount of material that a dike can entrain as it moves upward through a repository. The analysts found it possible to construct a probability distribution for this quantity by using field observations of the amount of material that past igneous intrusions have tom from the deep rock and carried to the surface. Distribuations for other quanúities, such as eruption voiume, were aiso derived from ñeid 


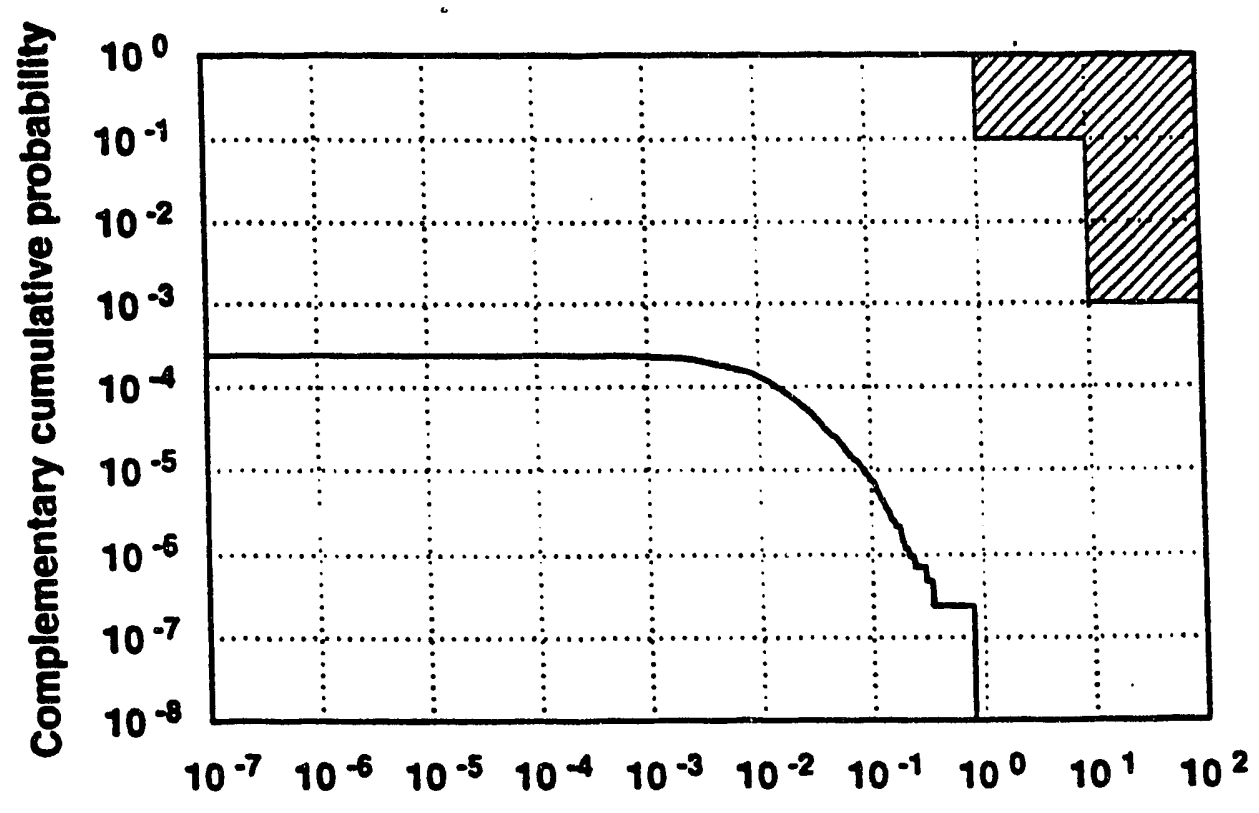

Normalized release to accessible environment

Figure 3. Cumulative complementary distribution for releases due to the igneous-intrusion sequence shown in Figure 2.

observations. In making these assignments, the authors worked both with the documents listed in Chapter 7 of Reference 1 and with the authors of those documents.

To obtain values for the probability of the sequence, the authors relied on additional field work. They computed a value for the overall probability of release due to volcanic activity by using estimates 2,3 of the frequency of volcanic eruptions.

With all this material, the study proceeded to construct a CCDF for igneous intrusion, represented by the dike sequence. Figure 3 displays the result. It shows that, if the assumptions made in the modeling are correct, a dike that cuts through the repository and carries waste to the surface would not cause a violation of the EPA

ui.

cas

standard. The CCDF lies so far from the limits that there appears to be little possibility of a violation unless some of the assumptions are wildly incorrect.

Nevertheless, the study included a number of sensitivity and uncertainty analyses. Figure 4 shows the effects of increases in the eruption volume and the fraction of rock torn from the wall alongside the dike. Other sensitivity analyses showed similar results. These CCDFs show little reason to suspect that further studies would demonstrate violations of the standard.

The igneous-intrusion studies suggest, then, that field work can supply data in ** support of convincing arguments about compliance with the EPA standard. The field work and its interpretation must pay careful attention to the objectives of examining compliance. Otherwise, they may not yield all the understanding that compliance. $\because$ analyses will need. The data cited here are particularly useful to the assessment: because they came from a program specifically designed to supply understanding for the examination of compliance.

It may be worthwhile to repeat that studies like these are not definitive estimates of compliance for Yucca Mountain. Much work remains to be done. For example, the igneous-intrusion studies will have to examine other sequences besides direct transport 


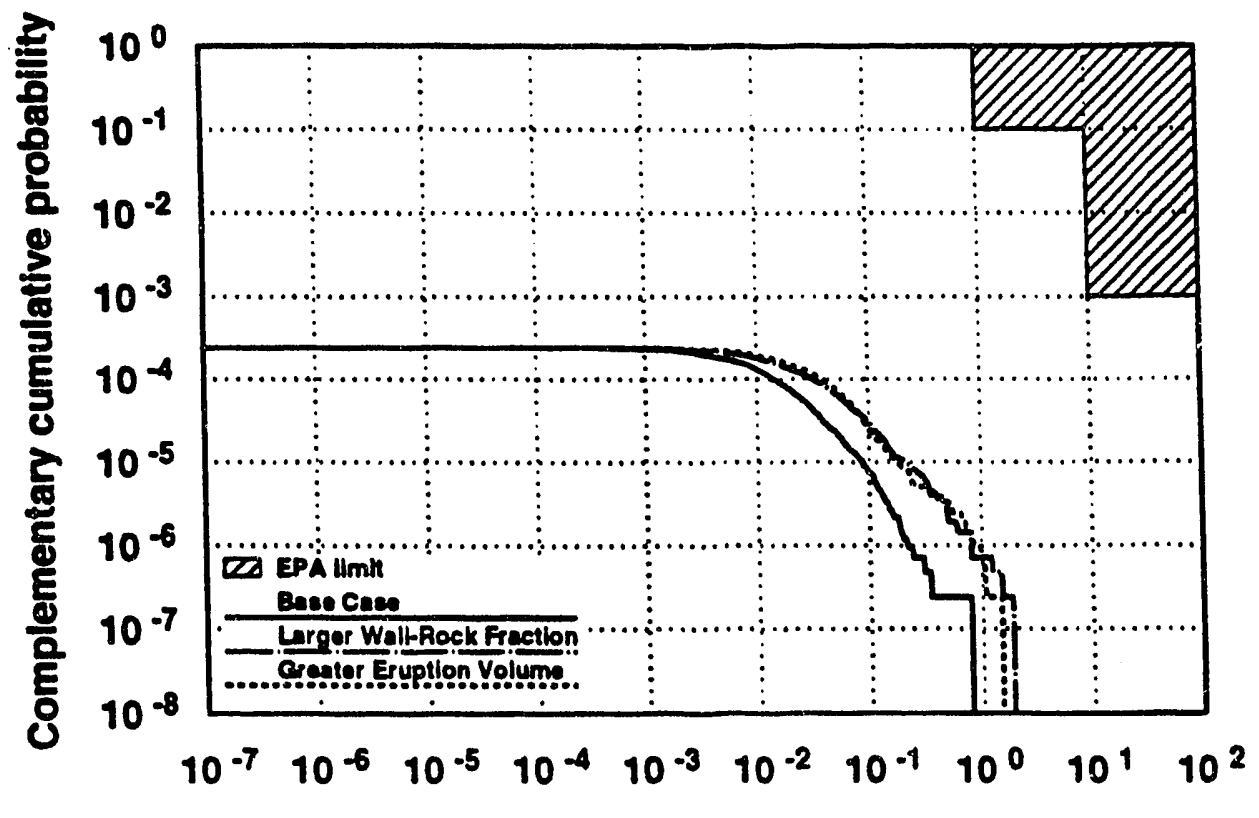

Normalized release to accessible environment

Figure 4. A sensitivity study for the igneous-intrusion calculation of releases. In addition to the complementary cumulative distribution from Figure 3, separate functions are shown for calculations that assume greater eruption volume and a larger fraction of rock torn from the walls of the intrusion.

in a dike. It will also be necessary to achieve a reasonable amount of consensus that the methods and results of the field studies are acceptable. Additional total-system analyses will supply the first of these example needs; the normal processes of peer review and comment, familiar to all workers in scientific fields today, will supply the second, especially when supplemented by special reviews by regulatory agencies. The lesson to be learned here is that a site-characterization program can provide Pderstanding directly applicable to examinations of compliance. This understanding I, it appears, come from studies that, if done carefully, may not require extraordinary - vances in the state of science. And if the results of the compliance analyses show Oompliance by a wide margin, the data will have contributed to the reasonable expectation that the standard seeks.

\section{Activity 3: constructing probability distributions}

Both of the two activities reviewed so far have touched on the subject of handling uncertainty. They suggest that uncertainty and sensitivity analyses are useful tools for examining compliance, especially when they embody carefully gathered site: data and treat alternative conceptual models appropriately.

They also show that a CCDF contains much information about uncertainty if the distributions assigned to parameters in the mathematical models account for the associated uncertainties. In preparing the total-system analysis, the authors of Reference 1 kept this principle in mind when they selected distributions. In addition to 
the kind of uncertainty treatment typified by the purposeful widening of the distribution for flux at depth, the authors derived some distributions by using a formal elicitation process that attempts to account for uncertainty explicitly and traceably.

This process stems from a desire to create distribution functions that not only express the natural distributions of quantities but also incorporate the uncertainty an analyst has in constructing a distribution from imperfect data. ${ }^{4}$ The foundation of the process is the notion of "informational entropy," a concept proposed in quantitative form more than four decades ago. 5 If an analyst does not know the true distribution of a quantity that is distributed in nature, the "maximum entropy formalism, " proposed by Jaynes, ${ }^{6}$ suggests that the most appropriate distribution is one that is (a) consistent with what is known about the natural distribution and (b) maximizes the information entropy. Harr has suggested ${ }^{7}$ that the beta distribution is a useful choice for the form of such distributions. It contains four adjustable parameters that can be chosen to represent the data describing a natural distribution.

As an experiment, the total-system assessment of Yucca Mountain used this process in constructing distributions for some of the parameters in its models-mostly parameters in the models of igneous intrusion, flow, and radionuclide transport. The process began with a review of existing data about the quantities whose distributions were to be constructed. This review also drew on the definitions of those quantities for additional information: for example, the width of a dike can never be less than zero, and the distribution of stich widths should incorporate that basic fact. Then the inalysts elicited the distributions from experts who used the data to estimate range, mean, and variability for each distributed parameter. In practice, the process used interactive graphics to facilitate the elicitation. After making a statement about range, mean, or variability, each expert could immediately see a computer-generated distribution that incorporated the statement. Figure 5 shows an example of such an elicited distribution. An important feature of the process was that the experts, in making their statements, were in continual communication with the total-system analysts. This feature helped to ensure that the information the experts were giving was what the analysts needed for their assessment.

When CCDFs are calculated from distributions constructed in this way, they display the effects of uncertainty. Because many of the most important parameters in the igneous-intrusion analysis were represented by distributions that explicitly incorporate the analysts' uncertainty, the dike-intrusion graphs (Figures 3 and 4) shown earlier are examples of such displays.

Part of the solution to the problem of handling uncertainty, then, is to construct probability distributions that express uncertainty and to use them in the models that describe the behavior of a repository system. Then the final CCDFs, which are the primary means of examining compliance, will take those uncertainties into account automatically. Perhaps even more important, the documentation describing the construction of the distributions will make explicit the methods, assumptions, and biases that underlie the CCDFs. This kind of explicitness will be essential when the technical community reviews future demonstrations of compliance.

The process that the Yucca Mountain assessment used will need further development; more use of it will help in understanding its strengths and weaknesses and in improving it. Nevertheless, the recent study, though preliminary, offers three lessons to be learned. (1) Uncertainties can be an explicit feature of the probabilistic 


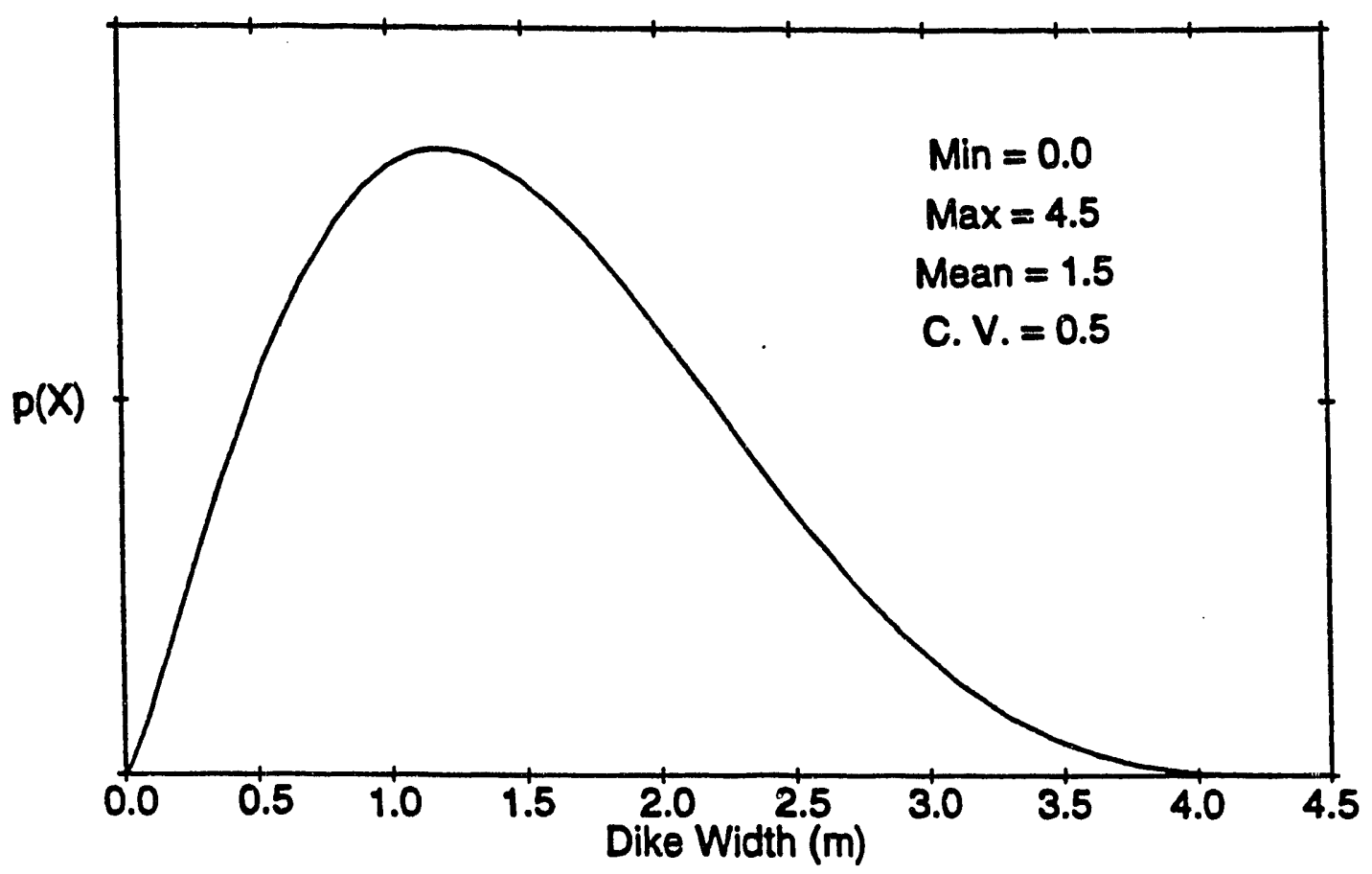

Figure 5. Distribution, obtained by elicitation, for widths of dikes that might form near Yucca Mountain.

treatment that the EPA standard demands. (2) The explicitness can facilitate review and comment during the process of examining compliance. (3) There appear to be simple methods for making uncertainties explicit-methods that, if developed further, may win the endorsement of the technical community.

\section{CONCLUSIONS: THE ANSWER TO THE QUESTION}

The conclusions to be drawn from this review are personal opinions. They cannot be said to follow rigorously from the review, which merely demonstrates possible solutions and does not prove compliance or lack of compliance of any potential repository system.

The recent total-system assessment uses techniques that are similar to what most observers of waste management probably see as techniques that regulators will expect in a licensing process. Although it does not have a complete base of information from which to draw, it suggests that such a base, when available after site characterization, can provide the information needed for examining compliance. And it suggests that the information needed for the examination is not impossible to gather, especially if the estimates of behavior turri out not to be close to the limits that the standard imposes. In these respects the assessment is grounds for optimism, as are other assessments that this paper does not review.

Before one can say, however, whether it is or is not possible to show compliance with the regulations, one must rsk an adcitional question. If assessments like the recent 
one are performed in the future-with all the benefits of site characterization and the resulting increases in understanding-will they meet the regulators' needs for "reasonable expectation"? That need, after all, is the final test of compliance, and analysts today can only guess what the regulators will ultimately regard as reasonable. Regulators clearly will require much more information than the recent assessment provides. But will they accept the treatment of conceptual models, field data, and uncertainties that the recent assessment suggests will be "reasonable" when supported by full site characterization?

Only the full licensing process will answer this question. I would say, though, that the prognosis for successful examinations of compliance is guardedly encouraging. At least, no one should now believe that no amount of data gathering and computer analysis can even address the EPA standard. To be sure, the licensing process will produce much disagreement and requests for additional understanding. The standard itself, however, does not seem impossible to use. And the review and criticism supplied by the technical community can go \& long way toward making "reasonable expectation" a reasonable objective to aim sian.

\section{REFERENCES}

1. R.W. Barnard, M.L. Wilson, H.A. Dockery, J.H. Gauthier, P.G. Kaplan, R.R. Eaton, F.W. Bingham, and T.H. Robey, TSPA 1991: An Initial Total-System Performance Assessment for Yucca Mountain. SAND91-2795, Sandia National Laboratories, Albuquerque, NM, 1992.

2. B.M. Crowe, S. Self, D. Vaniman, R. Amos, and F.V. Perry, J. Geol. 91, 259 (1983).

3. B.M. Crowe, Geological Soc. of America Abstracts 23(2), p. A16 (1991).

4. P.G. Kaplan, in High Level Radioactive Waste Management: Proceedings of the Second Annual International Conference, p. 1487 (1991).

5. C.E. Shannon, Bell Sys. Tech. J. 27, 379 (1948).

6. E.T. Jaynes, Phys. Rev. 108, 171 (1957).

7. M.E. Harr, Reliability-Based Design in Civil Engineering (McGraw-Hill Book Co., New York, 1987).

\section{DISCLAIMER}

\footnotetext{
This report was prepared as an account of work sponsored by an agency of the United States Government. Neither the United States Government nor any agency thereof, nor any of their employees, makes any warranty, express or implied, or assumes any legal liability or responsibility for the accuracy, completeness, or usefulness of any information, apparatus, product, or process disclosed, or represents that its use would not infringe privately owned rights. Reference herein to any specific commercial product, process, or service by trade name, trademark, manufacturer, or otherwise does not necessarily constitute or imply its endorsement, recommendation, or favoring by the United States Government or any agency thereof. The views and opinions of authurs expressed herein do not necessarily state or reflect those of the United States Government or any agency therenf.
} 

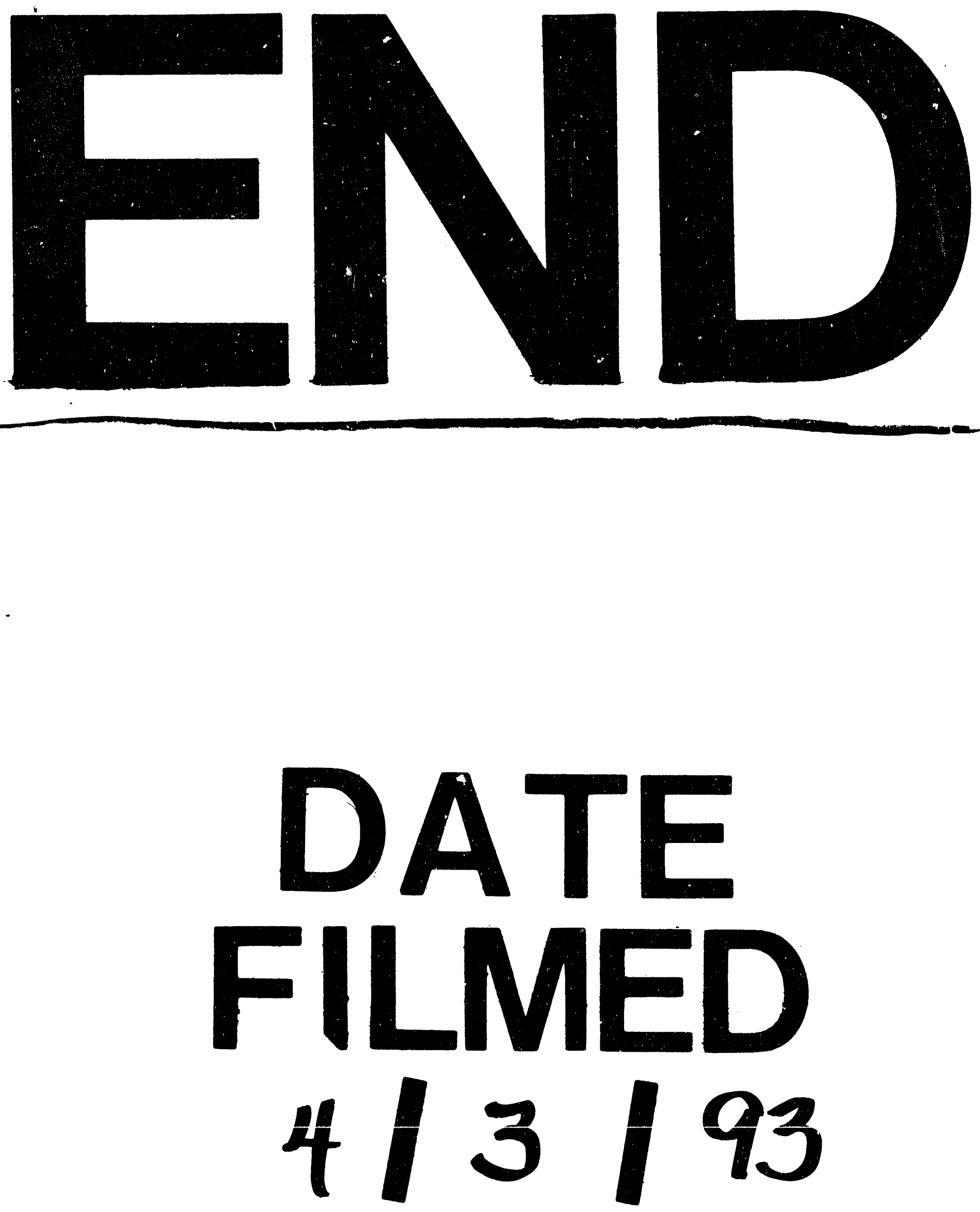
